\title{
Warping Torsional and Distortional Stress of Composited Box Girder with Corrugated Steel Webs
}

\author{
Peng Qiao $\mathbb{D}^{1}{ }^{1} \mathrm{Jin}_{\mathrm{Di}}{ }^{2,3}$ and Feng-jiang Qin ${ }^{2,3}$ \\ ${ }^{1}$ School of Civil Engineering, Chang'an University, Xian 710061, China \\ ${ }^{2}$ Key Laboratory of New Technology for Construction of Cities in Mountain Area (Chongqing University), Ministry of Education, \\ Chongqing 400045, China \\ ${ }^{3}$ School of Civil Engineering, Chongqing University, Chongqing 400045, China
}

Correspondence should be addressed to Peng Qiao; qiaopeng@chd.edu.cn

Received 25 October 2017; Revised 24 January 2018; Accepted 20 February 2018; Published 1 April 2018

Academic Editor: Roman Wendner

Copyright (C) 2018 Peng Qiao et al. This is an open access article distributed under the Creative Commons Attribution License, which permits unrestricted use, distribution, and reproduction in any medium, provided the original work is properly cited.

\begin{abstract}
The torsional behaviors of composite box girders with corrugated steel webs are more obvious than traditional concrete girders due to the lower torsional rigidity. In this paper, the torsion and distortion of this kind of composite girder are studied. The formulas for warping normal stress and shear stress were put forward according to the second theory of Umanskii, considering the accordion effect of corrugated steel webs. Then, the influences of different dimensional parameters on the torsional and distortional stress are investigated. Results show that the effect of parameters on stress is different and implicit in composite box girders with corrugated steel webs. Under eccentric loads, the warping torsional and distortional stress in this kind of girder should not be neglected. Compared with girders under corresponding symmetric loads, the total warping stress may be as big as flexural normal stress, and the total shear stress usually reaches 30 to 50 percentage of flexural shear stress. So the warping stress and additional shear stress due to warping torsion and distortion are suggested to be calculated by the proposed equations in structural analysis, which are usually not taken into account in conventional concrete box girders.
\end{abstract}

\section{Introduction}

The composite box girders with corrugated steel webs have been used more extensively in bridge engineering since first appearance in France. Under eccentric loads, the box girder may not only produce longitudinal flexural and shear deformation, but also the torsion and distortion. The torsional behaviors in these composite girders were found quite different from traditional concrete box girders [1]. Researchers worldwide have done much work on the torsional and distortional properties of composited box girder with corrugated steel webs. Mo et al. presented an analytical model to predict the torsional behavior of composite girders with corrugated steel webs [2] and developed an analytical model according to the test results [3]. According to experimental results of scaled models and bridge in site, Li et al. [4] and Liu et al. [5] concluded that resistance of this kind of box girder to torsion and distortion is lower than conventional box girders. Yang et al. investigated the warping and shear stress of the box girders with corrugated steel webs under torsion by the second theory of Umanskii [6]. Di et al. [7] and Wang [8] studied the torsional property of composite girders with corrugated steel webs by theoretical analysis and experiment and found its normal stress and shear stress due to torsion are $15 \%$ to $50 \%$ bigger than flexural normal stress and the distortional warping stress is larger than that due to warping torsion. Nie and Zhang [9] and Chen et al. [10] studied the influencing factors to torsional properties by finite element method, including the diaphragm number, geometry parameters of section, and corrugated web. Ding et al. investigate the behavior under pure torsion and the ultimate torsional strength considering material nonlinearity by finite element models [11] and scaled specimen experiments [12]. According to current studies, the additional normal and shear stress caused by torsion and distortion should be considered properly, which is often neglected for concrete box girders. 


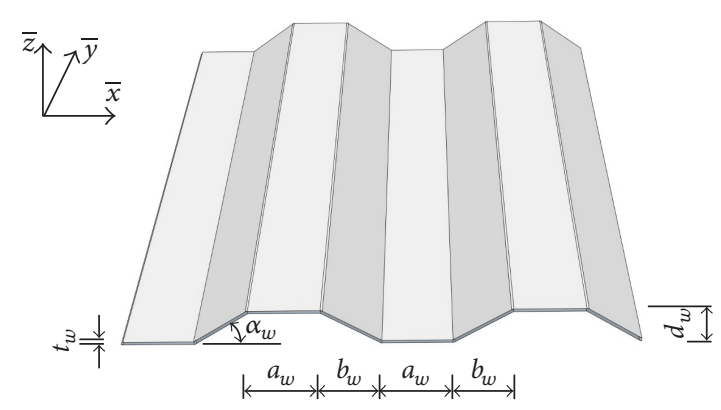

FIGURE 1: Geometry of the corrugated web.

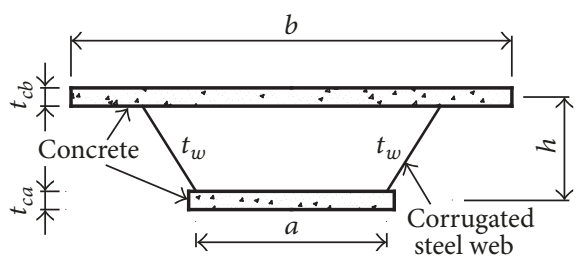

(a) Composite section

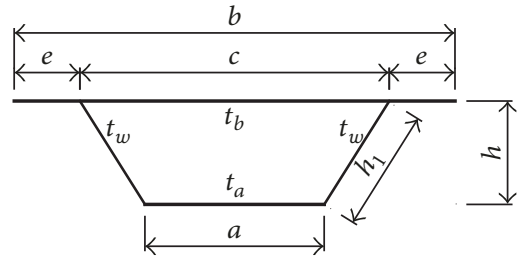

(b) Equivalent section

Figure 2: Geometry of equivalent section.

But little detailed conclusions are found on how the section dimensions influence the torsional and distortional stress.

As to composite box girders with corrugated steel webs, the $3 \mathrm{D}$ finite element models are rather complex to build. So, the theoretical analysis, based on the thin-walled beam theory, can be used more conveniently to study the mechanical properties of such composite structures. In the theoretical deduction process, the accordion effect of corrugated steel web should be considered correctly, as discussed by Yang et al. [6]. However, there were still some improper results from current studies. For example, the web shear stress is not influenced by the warping torsion, or the shear stress is not even in web. Additionally, the formula of distortional shear stress has not yet been proposed explicitly. The purpose of this paper is to propose formulas for warping torsional and distortional shear stress and study the influences of different factors to the warping torsional and distortional stress compared to the flexural normal stress.

\section{Equivalent Section}

2.1. Equivalent Orthotropic Plate of the Corrugated Steel Web. The geometry of the typical corrugated web is shown in Figure 1. The corrugated steel web is recommended to be equivalent to the orthotropic plate $[13,14]$, which has different elastic modulus in $\bar{x}$ and $\bar{y}$ direction:

$$
\begin{aligned}
& E_{\bar{x}}=\frac{a_{w}+b_{w}}{4 a_{w}}\left(\frac{t_{w}}{d_{w}}\right)^{2} E_{s}, \\
& E_{\bar{y}}=\frac{a_{w}+b_{w} \sec \alpha_{w}}{a_{w}+b_{w}} E_{s},
\end{aligned}
$$

where
$E_{s}$ is Young's modulus of steel;

$E_{\bar{x}}, E_{\bar{y}}$ are the equivalent elastic modulus in $\bar{x}$ and $\bar{y}$ direction, respectively;

$a_{w}, b_{w}, d_{w}, \alpha_{w}$ are flat panel width, inclined panel width, wave height, angle of the corrugated web, respectively.

According to (1), the axial stiffness in longitudinal direction can be neglected, for the ratio of $t_{w}$ and $d_{w}$ of a corrugated web is always less than $1 / 100$.

Additionally, the effective shear modulus of a corrugated web [15], $G_{e}$, is given by

$$
G_{e}=\frac{a_{w}+b_{w}}{a_{w}+b_{w} \sec \alpha_{w}} G_{s},
$$

in which $G_{s}$ is the shear modulus of steel.

2.2. Equivalent Section of Composite Box Girders with Corrugated Steel Webs. In order to directly adopt the thin-walled box girder theory to analyze the mechanical properties of the composite box girders with corrugated steel webs, the composite section is transformed to an equivalent cross section of single material, as shown in Figure 2. Considering the corrugated webs bear most of shear force in composite box girder, the cross section is assumed to be composed of steel material alone.

Assuming that the shearing force and stress remain the same, the equivalent thickness of concrete slab, $t$, is given by

$$
t=\frac{G_{c}}{G_{e}} \cdot t_{c}=n^{\prime} \cdot t_{c},
$$

where 
$t_{c}$ is the thickness of concrete slab in composite box section;

$G_{c}$ is the shear modulus of concrete;

$n^{\prime}$ is the ratio of shear modulus of concrete and corrugated steel web.

\section{Warping Torsional Stress}

3.1. Torsional Warping Stress. According to the second theory of Umanskii, the warping displacement caused by warping torsion is given by

$$
u(z)=u_{0}(z)-\bar{\omega} \beta^{\prime}(z),
$$

in which $\bar{\omega}$ is the principal unit warping (sectorial coordinate). Its practical formulas may be found in [16-18].

The torsional warping normal stress, $\sigma_{\omega}$, is determined from the bimoment:

For concrete slab,

$$
\sigma_{\omega}=\frac{B_{\bar{\omega}} \cdot \bar{\omega}}{I_{\bar{\omega}}} .
$$

For corrugated steel web,

$$
\sigma_{\omega}=\frac{E_{\bar{x}}}{E_{\bar{y}}} \frac{B_{\bar{\omega}} \cdot \bar{\omega}}{I_{\bar{\omega}}} \approx 0,
$$

where

$B_{\bar{\omega}}$ is the warping bimoment caused by warping torsion;

$I_{\bar{\omega}}$ is the warping torsional inertia. For composite box girder with corrugated steel webs, it is given by

$$
I_{\bar{\omega}}=\int_{b} \bar{\omega}^{2} d A+\int_{a} \bar{\omega}^{2} d A+2 \frac{E_{\bar{x}}}{E_{\bar{y}}} \int_{w} \bar{\omega}^{2} d A .
$$

Considering that the ratio $E_{\bar{x}} / E_{\bar{y}}$ of corrugated steel web is small enough to ignore, the warping torsional inertia is simplified by

$$
I_{\bar{\omega}}=\int_{b} \bar{\omega}^{2} d A+\int_{a} \bar{\omega}^{2} d A
$$

in which the subscripts $a$ and $b$ indicate the bottom and top slab, respectively. Equation (9) is used in formulas to calculate warping normal stress for composite girder with corrugated steel webs, which has already been given in [6].

3.2. Total Torsional Shear Stress. The deduction procedure of shear stress for composite box girder with corrugated steel web is similar to that of concrete box girder. However, the accordion effect of corrugated steel web should be considered correctly.

The shear flow in slab can be determined by the warping normal stress considering the equilibrium in the longitudinal direction of a plate element:

$$
\frac{\partial q}{\partial s} d s=-\frac{\partial \sigma_{\omega}}{\partial z} t d s
$$

The shear flow in different plate is shown as follows.
For equivalent cantilever slab,

$$
q(s)=E_{\bar{y}} \beta^{\prime \prime \prime}(z) \int_{0}^{s} \bar{\omega} d A=E_{\bar{y}} \beta^{\prime \prime \prime}(z) \cdot S_{\bar{\omega}}(s) .
$$

For equivalent top and bottom slab,

$$
\begin{aligned}
q(s) & =E_{\bar{y}} \beta^{\prime \prime \prime}(z) \int_{0}^{s} \bar{\omega} d A+q_{0} \\
& =E_{\bar{y}} \beta^{\prime \prime \prime}(z) \cdot S_{\bar{\omega}}(s)+q_{0} .
\end{aligned}
$$

For corrugated steel web,

$$
\begin{aligned}
q(s) & =E_{\bar{x}} \beta^{\prime \prime \prime}(z) \int_{0}^{s} \bar{\omega} d A+q_{0} \\
& =E_{\bar{x}} \beta^{\prime \prime \prime}(z) \cdot S_{\bar{\omega}}(s)+q_{0},
\end{aligned}
$$

where

$$
S_{\bar{\omega}}(s)=\int_{0}^{s} \bar{\omega} d A
$$

Noting that the external torque is $M_{k}$ equal to the total action of $q$, we get

$$
\begin{aligned}
M_{k}(z) & =\oint q(s) \rho(s) d s \\
& =q_{0} \Omega+E_{\bar{y}} \beta^{\prime \prime \prime}(z) \cdot \oint S_{\bar{\omega}} d \omega,
\end{aligned}
$$

where

$$
\begin{aligned}
\Omega= & \oint \rho(s) d s \\
\oint S_{\bar{\omega}}(s) d \omega= & \int_{b} S_{\bar{\omega}}(s) d \omega+\int_{a} S_{\bar{\omega}}(s) d \omega \\
& +\frac{E_{\bar{x}}}{E_{\bar{y}}} \int_{w} S_{\bar{\omega}}(s) d \omega \\
\approx & \int_{b} S_{\bar{\omega}}(s) d \omega+\int_{a} S_{\bar{\omega}}(s) d \omega .
\end{aligned}
$$

In (17), it is noted that the ratio $E_{\bar{x}} / E_{\bar{y}}$ of corrugated steel web is small enough to ignore corrugated steel webs.

From (15),

$$
q_{0}=\frac{M_{k}(z)}{\Omega}-\frac{E_{\bar{y}} \beta^{\prime \prime \prime}(z)}{\Omega} \oint S_{\bar{\omega}} d \omega .
$$

The warping torsional moment derived from torsional warping bimoment is

$$
M_{\bar{\omega}}=\frac{d B_{\bar{\omega}}(z)}{d z}=-E_{\bar{y}} I_{\bar{\omega}} \beta^{\prime \prime \prime}(z) .
$$

Substituting (18) and (19) into (11) (13), the total shear stress considering the warping torsion can be determined from torsion and warping torsional moment:

$$
\tau(s)=\frac{M_{k}(z)}{t \Omega}-\frac{M_{\bar{\omega}}}{I_{\bar{\omega}} t} \bar{S}_{\bar{\omega}}(s),
$$

in which $\bar{S}_{\bar{\omega}}(s)$ is the generalized area moment of inertia. 
For equivalent cantilever slab,

$$
\bar{S}_{\bar{\omega}}=S_{\bar{\omega}} .
$$

For equivalent top and bottom slab,

$$
\bar{S}_{\bar{\omega}}=S_{\bar{\omega}}-\frac{\oint S_{\bar{\omega}} d \omega}{\Omega} .
$$

For corrugated steel web,

$$
\bar{S}_{\bar{\omega}}=-\frac{\oint S_{\bar{\omega}} d \omega}{\Omega} .
$$

3.3. Differential Equation. Considering the longitudinal displacement closure condition, the differential equation is deduced:

$$
\beta^{I V}(z)-k^{2} \beta(z)=-\frac{m \mu}{E I_{\bar{\omega}}}
$$

in which $m$ is load intensity of torque; $\mu$ is the restrained constant of section; $k$ is the moment-torsional coefficient, defined by

$$
k^{2}=\mu \frac{G_{e} I_{d}}{E_{\bar{y}} I_{\bar{\omega}}},
$$

in which $G_{e} I_{d}$ is the torsional rigidity; $E_{\bar{y}} I_{\bar{\omega}}$ is the warping torsional rigidity. According to specific boundary conditions, the above differential equation can be solved by initialparameter method in $[19,20]$.

\section{Distortional Stress}

4.1. Distortional Warping Stress. According to [20], the distortional warping stress of composite box girder with corrugated steel web has already been given. The most important equations are list as follows.

The distortional differential equation of distortional angle, $\gamma$, is

$$
E I_{\omega_{D}} \gamma^{(4)}+E I_{R} \gamma=\frac{a^{2}}{a+c} P(z)
$$

in which $E I_{\omega_{D}}$ is distortional warping rigidity, $E I_{R}$ is distortional rigidity of transverse frame, and $P(z)$ is antisymmetric load at intersection point of top slab.

Combined with specific boundary conditions, the analytical solutions of distortional angle, $\gamma$, and distortional bimoment, $B_{D}$, can be deduced by initial-parameter method. Then the distortional warping normal stress is given as follows:

$$
\begin{gathered}
\sigma_{D a}=\frac{B_{D}}{I_{\omega_{D}}} \omega_{D a}, \\
\sigma_{D b}=\frac{B_{D}}{I_{\omega_{D}}} \omega_{D b},
\end{gathered}
$$

in which $\sigma_{D a}, \sigma_{D b}$ are the warping stress at the junction between bottom and top slab, respectively. $\omega_{D a}=K_{4}, \omega_{D b}=$ $\beta K_{4}$. The coefficients $\beta$ and $K_{4}$ can be calculated according to [20].
4.2. Distortional Shear Stress. Little has been studied on the distortional shear stress of composite box girder with corrugated steel webs. So the additional shear stress due to distortion is deduced as follows.

The distortional shear moment is given by

$$
M_{D}(z)=\frac{d B_{D}(z)}{d z}=-E \widehat{I} \gamma^{\prime \prime \prime}
$$

Then, the distortional shear force in different slabs can be calculated as follows.

For corrugated steel web,

$$
Q_{1}=\frac{M_{D}(z)}{a \sin \theta} .
$$

For equivalent bottom slab,

$$
Q_{2}=\frac{c}{h_{1}} Q_{1}=\frac{c M_{D}(z)}{h_{1} a \sin \theta} .
$$

For equivalent top slab,

$$
Q_{4}=\frac{a}{h_{1}} Q_{1}=\frac{M_{D}(z)}{h_{1} \sin \theta} .
$$

The distortional shear stress is given by

$$
\tau_{D i}=\frac{Q_{i}}{A_{i}},
$$

in which $A_{i}$ is the cross-sectional area of equivalent top, bottom, or web slab. Because of the changing of normal stress due to distortional warping, the additional shear stress is also produced. The additional shear stress can be deduced by similar procedures like warping torsional shear stress, and it should be considered that no torsional force in section is generated under distortion. Thus, the distortional additional shear stress can be calculated by

$$
\tau_{D \omega}(s)=-\frac{M_{D}}{I_{\omega_{D}} t} \bar{S}_{\omega_{D}}(s),
$$

in which $\bar{S}_{\omega_{D}}(s)$ is the generalized area moment of inertia.

For equivalent cantilever slab,

$$
\bar{S}_{\omega_{D}}=S_{\omega_{D}}
$$

For equivalent top and bottom slab,

$$
\bar{S}_{\omega_{D}}=S_{\omega_{D}}-\frac{\oint S_{\omega_{D}} d \omega}{\Omega} .
$$

For corrugated steel web,

$$
\bar{S}_{\omega_{D}}=-\frac{\oint S_{\omega_{D}} d \omega}{\Omega},
$$




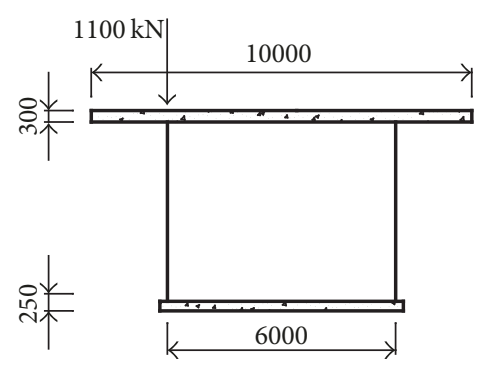

(a) Cross section

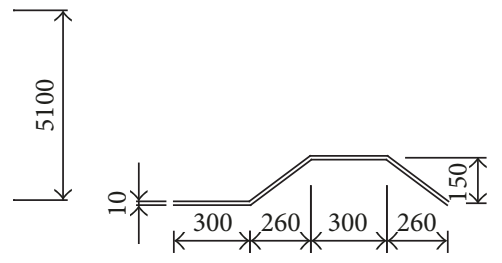

(b) Corrugated steel web

FIGURE 3: Configurations and dimension of specimens in case 1 (unit: $\mathrm{mm}$ ).

where

$$
\begin{aligned}
S_{\omega_{D}}(s) & =\int_{0}^{s} \omega_{D} d A, \\
\oint S_{\omega_{D}}(s) d \omega & \approx \int_{b} S_{\omega_{D}}(s) d \omega+\int_{a} S_{\omega_{D}}(s) d \omega .
\end{aligned}
$$

Finally, the total distortional shear stress is as follows:

$$
\tau_{D i}=\frac{Q_{i}}{A_{i}}-\frac{M_{D}}{I_{\omega_{D}} t} \bar{S}_{\omega_{D}}(s) .
$$

According to the above equation, the distortional shear stress is comprised of two parts, which are the direct shear stress due to distortional shear force and the additional shear stress due to changing normal stress, just like the warping torsional shear stress.

\section{Comparative Studies}

5.1. Case 1. Take the simple supported composite girder with corrugated steel webs in [21] as an illustration (as shown in Figure 3). The span, $L$, is $43.2 \mathrm{~m}$. The height, $h$, is $5.1 \mathrm{~m}$. The top slab width, $b$, is $10 \mathrm{~m}$ and thickness, $t_{c b}$, is $0.30 \mathrm{~m}$. The bottom slab width, $a$, is $6 \mathrm{~m}$ and thickness, $t_{c a}$, is $0.25 \mathrm{~m}$. For the corrugated steel webs, the thickness, $t_{w}$, is $0.01 \mathrm{~m}$, the panel width $a_{w}$ is $0.30 \mathrm{~m}, b_{w}$ is $0.26 \mathrm{~m}$, and $d_{w}$ is $0.15 \mathrm{~m}$. For concrete, $E_{c}$ is $3.4 \times 10^{4} \mathrm{MPa}$ and $\mu_{c}$ is 0.1667 . For steel, $E_{s}$ is $2.1 \times 10^{5} \mathrm{MPa}$ and $\mu_{s}$ is 0.3 . The $1100 \mathrm{kN}$ eccentric load is applied at one conjunction of web on the top slab at the midspan cross section.

Using the finite element program ANSYS, 3D models of composite girders were built to verify the above theoretical analysis expressions. The eight-node Solid element (SOLID45) was used to model the concrete slabs. The fournode Shell element (SHELL63) was chosen to simulate the corrugated steel webs. The concrete and steel materials were linear elastic and no plastic or strain hardening was taken into account. The slip and composite action between the concrete slab and steel web were neglected, so the concrete and steel nodes on their interface were merged to ensure they had the same deformation. As the girder is assumed to be simple supported at both ends, four nodes at the bottom were constrained as shown in Figure 4. Nodes no. 1 to 4 were provided constraints in different directions, but no rotating constraint was given. In finite element analysis (FEA), the torsional loads and the distortional loads were separately applied on nodes of top and bottom concrete slab and steel webs in the mid-span section of the girder.

The warping normal stress and shear stress of this composite girder are shown in Figure 5. As the normal stress in corrugated webs and shear stress in concrete slabs are rather small, only the normal stress in concrete slabs and shear stress in corrugated webs are given. In order to verify the results according to equations in this paper, the stress calculated by FEA is presented separately in bracket [].

As shown in Figure 5, the above equations of warping normal stress and shear stress for composite girder with corrugated steel webs are verified by FEA results. Compared with stress due to distortion, the warping normal stress due to warping torsion is much smaller, while the shear stress in webs is a little bigger. Noticing that the flexural normal stress in bottom slab is $1.45 \mathrm{MPa}$ and the flexural shear stress in webs is $5.39 \mathrm{MPa}$, the distortional warping stress is even as big as flexural normal stress. This means the influence of both warping torsion and distortion on normal and shear stress must be considered properly. In this girder, the normal stress in bottom slab due to warping torsion has the opposite direction to stress due to distortion.

The results of warping normal stress and web shear stress were also displaced in Figure 6, comparing with the stress according to analytical equations. As shown in Figure 6, the stress from two different methods has little discrepancy, which means the analytical equations in this essay are effective.

5.2. Case 2. Take the simple supported composite girder with corrugated steel webs in [6] as another illustration (as shown in Figure 7). The span, $L$, is $7.5 \mathrm{~m}$. The height, $h$, is $0.3688 \mathrm{~m}$. The top slab width, $b$, is $1.8 \mathrm{~m}$ and thickness, $t_{c b}$, is $0.1125 \mathrm{~m}$. The bottom slab width, $a$, is $0.4626 \mathrm{~m}$ and thickness, $t_{c a}$, is $0.11 \mathrm{~m}$. For the corrugated steel webs, the thickness, $t_{w}$, is $0.003 \mathrm{~m}$, the panel width $a_{w}$ is $0.063 \mathrm{~m}, b_{w}$ is $0.050 \mathrm{~m}$, and $d_{w}$ is $0.038 \mathrm{~m}$. For concrete, $E_{c}$ is $3.4 \times 10^{4} \mathrm{MPa}$ amd $\mu_{c}$ is 0.1667 . For steel, $E_{s}$ is $2.1 \times 10^{5} \mathrm{MPa}$ and $\mu_{s}$ is 0.3 . The $20 \mathrm{kN}$ eccentric load is applied at one conjunction of web on the top slab at mid-span section.

Based on equations for warping torsional and distortional stress, the warping normal stress and shear stress of the composite girder are shown in Figure 8. To verify the results, 


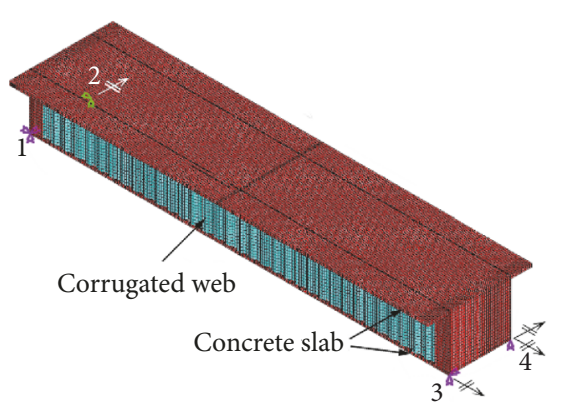

$\# \rightarrow$ Movable direction

(a) Girder model

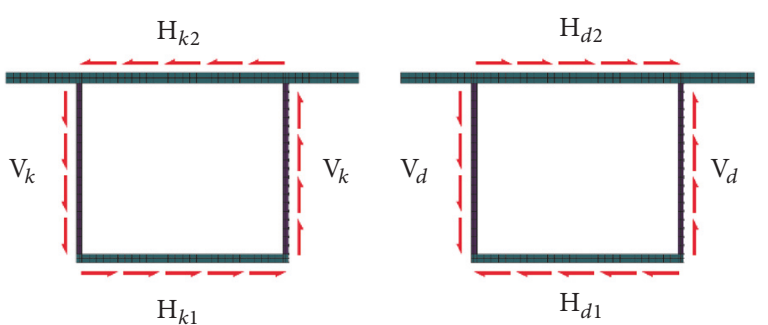

(b) Torsional loads and distortional loads

FIGURE 4: Finite element model of composite girder in [21].

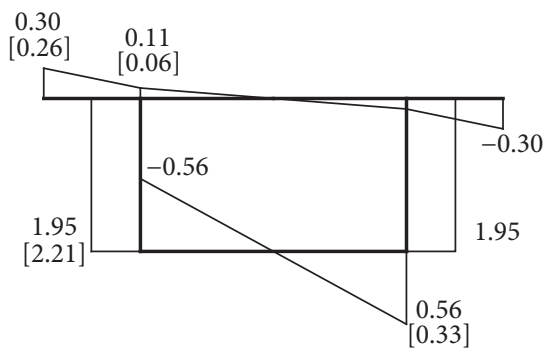

(a) Warping torsional stress

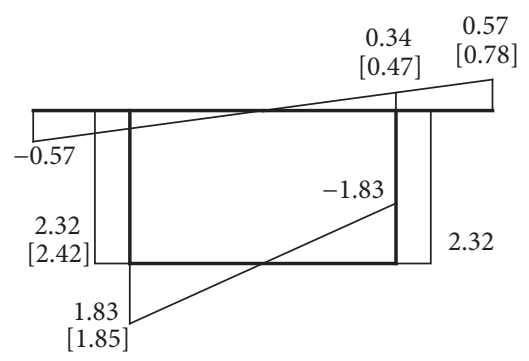

(b) Distortional stress

FIGURE 5: Warping normal stress and shear stress of composite girder in [21] (unit: MPa).

stress results from $[6,20]$ and stress calculated by FEA are presented separately in brackets () and [].

Figure 8 shows that the above equations of warping normal stress and shear stress are verified by FEA results again. The warping torsional shear stress calculated by equations in this paper is $80 \%$ smaller than that in $[6,20]$, because the accordion effect of corrugated steel web is considered to get the generalized area moment of inertia, $\bar{S}_{\bar{\omega}}(s)$. It should be also noted that the additional shear stress due to restrained torsion has the opposite direction to the free torsional stress, which may reduce the total shear stress. The shear stress due to warping torsion is smaller than that by distortion. Additionally, the warping normal stress in bottom slab is much bigger than stress in top slab for trapezoidal sections. Besides, the normal stress in bottom slab caused by warping torsion has the opposite direction to stress due to distortion.

On the corresponding symmetric load condition, the flexural normal stress in bottom slab is $1.91 \mathrm{MPa}$ and the flexural shear stress in webs is $4.52 \mathrm{MPa}$. The above results show that the total warping stress in this trapezoidal composite box girder is small, but the total shear stress due to torsion and distortion is 30 percent of flexural shear stress and must be calculated properly.

\section{Parametric Analysis}

According to the above two examples, the influence of torsion and distortion on stress is different if dimensional parameters of composite box girder change. When calculating the warping torsional and distortional stress, the warping rigidity and transverse form rigidity are not easy to be derived. Besides the fact that the equations for normal and shear stress are complex, it is difficult to find the explicit relationship between girder dimension parameters and warping torsional and distortional rigidity or stress. So, the parametric analysis needs to be done to study how these parameters influence the warping torsion and distortion behaviors for composite girder with corrugated steel webs.

The composite girder dimensions in [21] were used to analyze the torsional and distortional stress under eccentric load at mid-span section under the simple supported boundary condition. The following analysis covers parameters including the span length and section height of girder, the width and thickness of top and bottom flange, and the dimensions of corrugated steel web. Only one parameter is changed in each analysis. The normal stress on the bottom slab at the conjunction of web and web shear stress at midspan section were studied to compare the effect of warping torsion and distortion.

Six coefficients were defined to analyze the influence of warping torsion and distortion on the normal stress and shear stress, which are

$$
\begin{aligned}
& \eta_{1}=\left|\frac{\sigma_{\omega}}{\sigma_{M}}\right|, \\
& \eta_{2}=\left|\frac{\sigma_{D \omega}}{\sigma_{M}}\right|,
\end{aligned}
$$




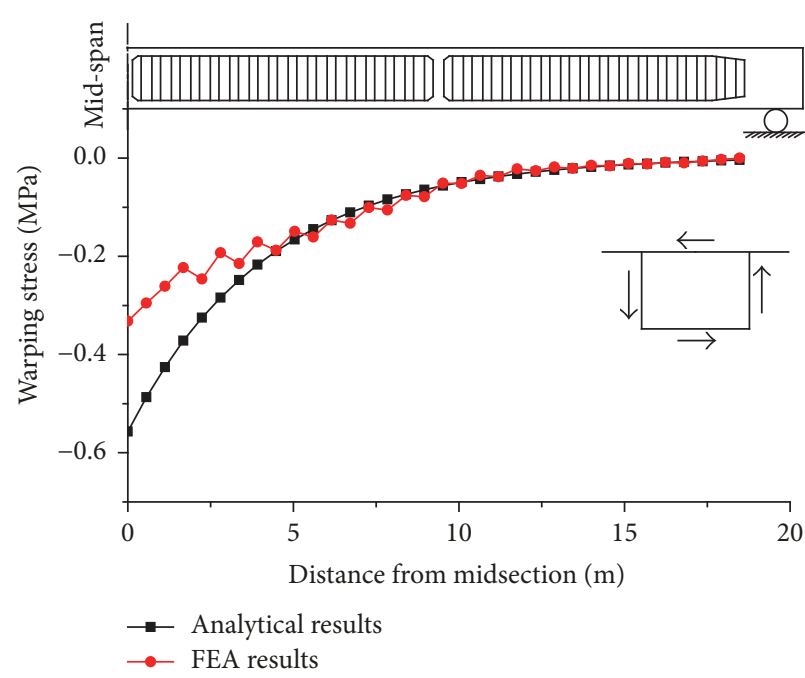

(a) Torsional warping stress in bottom slab

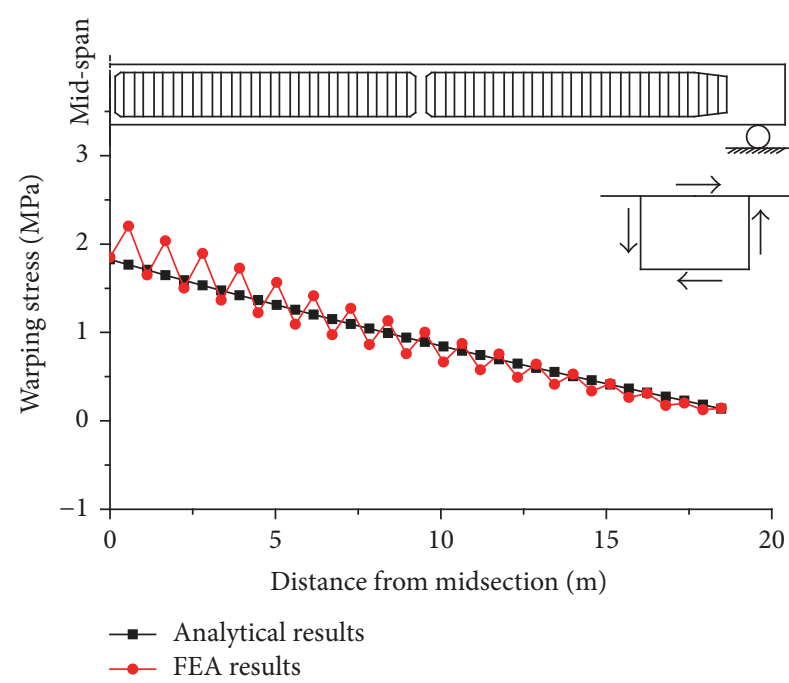

(c) Distortional warping stress in bottom slab

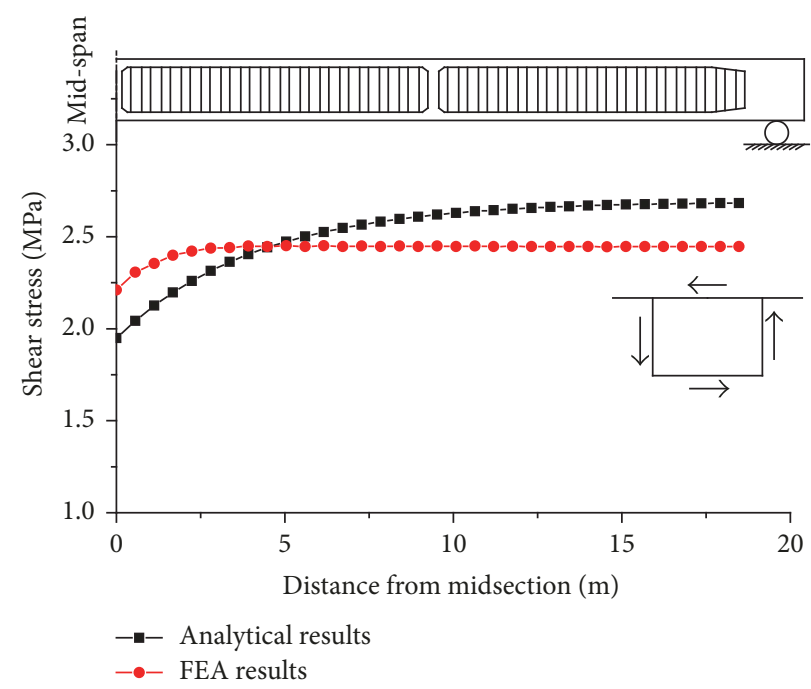

(b) Torsional shear stress in web

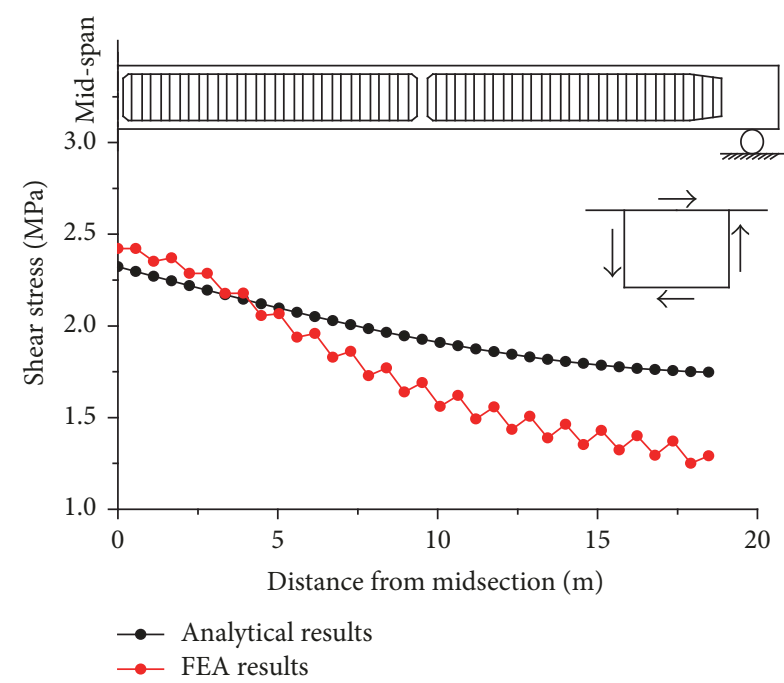

(d) Distortional shear stress in web

Figure 6: Stress by FEA and analytical equations.

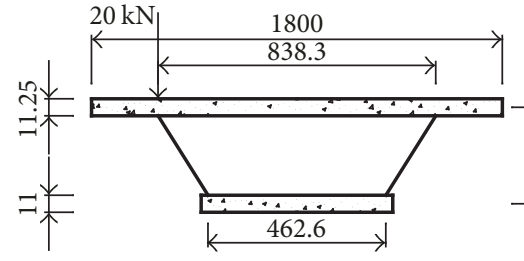

(a) Cross section

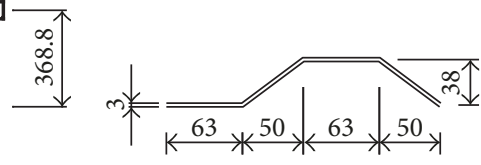

(b) Corrugated steel web

Figure 7: Configurations and dimension of specimens in case 2 (unit: $\mathrm{mm}$ ).

$$
\begin{aligned}
& \eta_{3}=\frac{\left(\tau_{k}+\tau_{\omega}\right)}{\tau_{M}}, \\
& \eta_{4}=\frac{\left(\tau_{D}+\tau_{D \omega}\right)}{\tau_{M}}, \\
& \eta_{5}=\frac{\tau_{\omega}}{\tau_{k}}
\end{aligned}
$$$$
\eta_{6}=\frac{\tau_{D \omega}}{\tau_{D}}
$$

where $\sigma_{M}, \sigma_{\omega}, \sigma_{D}$ are normal stress separately caused by bending, torsional warping, and distortional warping; $\tau_{M}, \tau_{k}$, $\tau_{\omega}, \tau_{D}, \tau_{D \omega}$ are shear stress separately caused by bending, free 


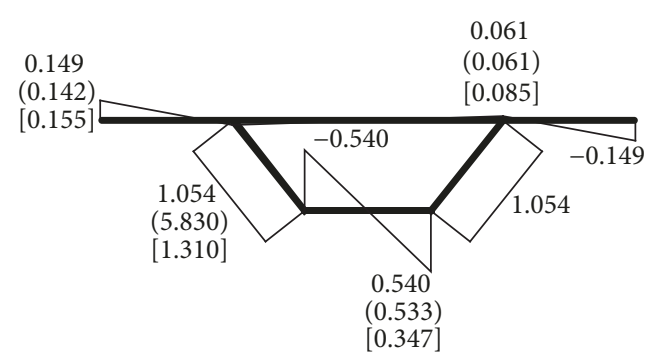

(a) Warping torsional stress

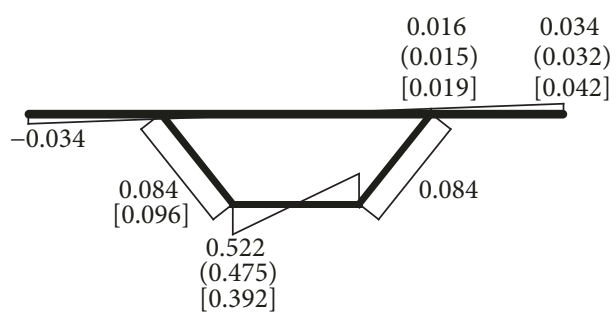

(b) Distortional stress

FIGURE 8: Warping normal stress and shear stress of composite girder in [6] (unit: MPa).
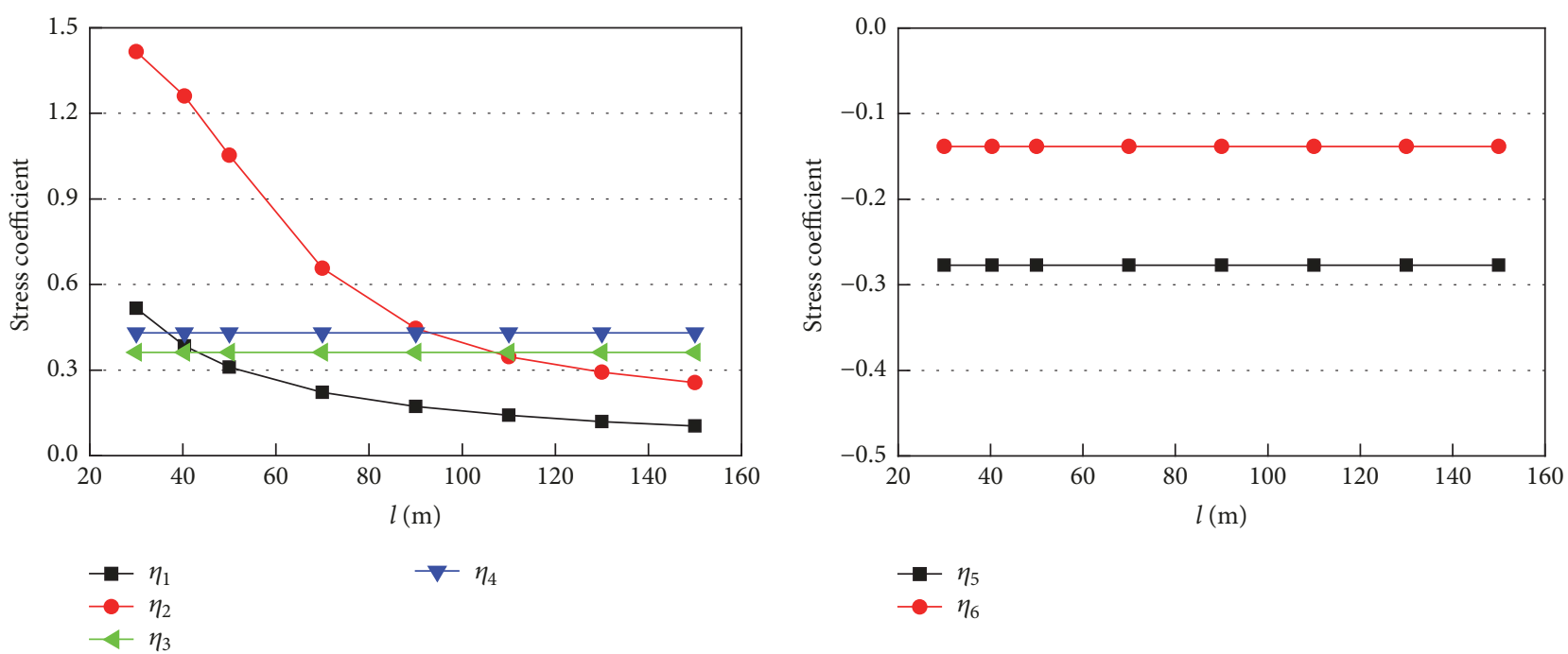

FIgURE 9: Stress coefficients versus different span length.

torsion, warping torsion, pure distortion, and distortional addition.

The coefficients $\eta_{1}, \eta_{2}$ imply the influence of warping torsion and distortion on normal stress, and $\eta_{3}, \eta_{4}$ imply the influence on shear stress. The coefficients $\eta_{5}, \eta_{6}$ imply the additional shear stress due to changing of normal stress caused by warping torsion and distortion.

6.1. Effect of Span Length. When the span length is separately $30,40,50,70,90,110,130$, and $150 \mathrm{~m}$, the variation of stress coefficients is given in Figure 9. The span length had obvious influence only on both warping normal stress but not shear stress. The effects of torsion and distortion were reduced if the girder span got longer; the coefficient $\eta_{1}$ changed from 0.52 to 0.10 , and $\eta_{2}$ changed from 1.42 to 0.26 . On most conditions of girder span within $80 \mathrm{~m}$, the torsional and distortional warping stress are more than $30 \%$ of flexural normal stress. So the warping normal stress needs to be considered in normal stress check in structural design.

6.2. Effect of Section Height. The section height is generally $1 / 40$ to $1 / 25$ of the span length. Here, the height is set to be 2.5, $3.8,5.1,6.4,7.7,9.0,10.3,11.6$, and $12.9 \mathrm{~m}$. The variation of stress coefficients for different height is given in Figure 10. As the girder height got bigger, the coefficients of normal stress got bigger obviously. The coefficient $\eta_{1}$ changed from 0.19 to 0.66 and $\eta_{2}$ changed from 0.72 to 1.48 . The shear stress coefficients $\eta_{3}$ and $\eta_{4}$ had small change by less than 0.05 . It shows that the influence of section height is much more obvious to warping normal stress than shear stress.

6.3. Effect of Top Flange Width. In following analysis, the girder section is rectangular whose corrugated steel webs are vertical. When the top flange width, measured width between webs, is separately $4,5,6,7$, and $8 \mathrm{~m}$, the variation of stress coefficients is given in Figure 11. Only the coefficient $\eta_{1}$ nearly remained constant as the chamber width grows, but other coefficients changed. $\eta_{2}$ grew from 0.95 to 1.39 . The coefficients $\eta_{3} \sim \eta_{6}$ changed separately from $0.28,0.39,-0.44$, -0.22 to $0.41,0.46,-0.17$, and -0.09 . Thus, the influence of top flange width is not ignorable.

6.4. Effect of Cantilever Flange Width. The cantilever flange width (flange width between a web and a free edge) is usually designed within one-half of the top flange width between webs. As the top flange width is $6.0 \mathrm{~m}$, the cantilever flange width is accordingly proposed to be $0,0.5,1.0,1.5,2.0,2.5$, and $3.0 \mathrm{~m}$, respectively. The variation of stress coefficients is given in Figure 12. As the cantilever flange width got bigger, the normal stress coefficients $\eta_{1}$ and $\eta_{2}$ changed in a limit 

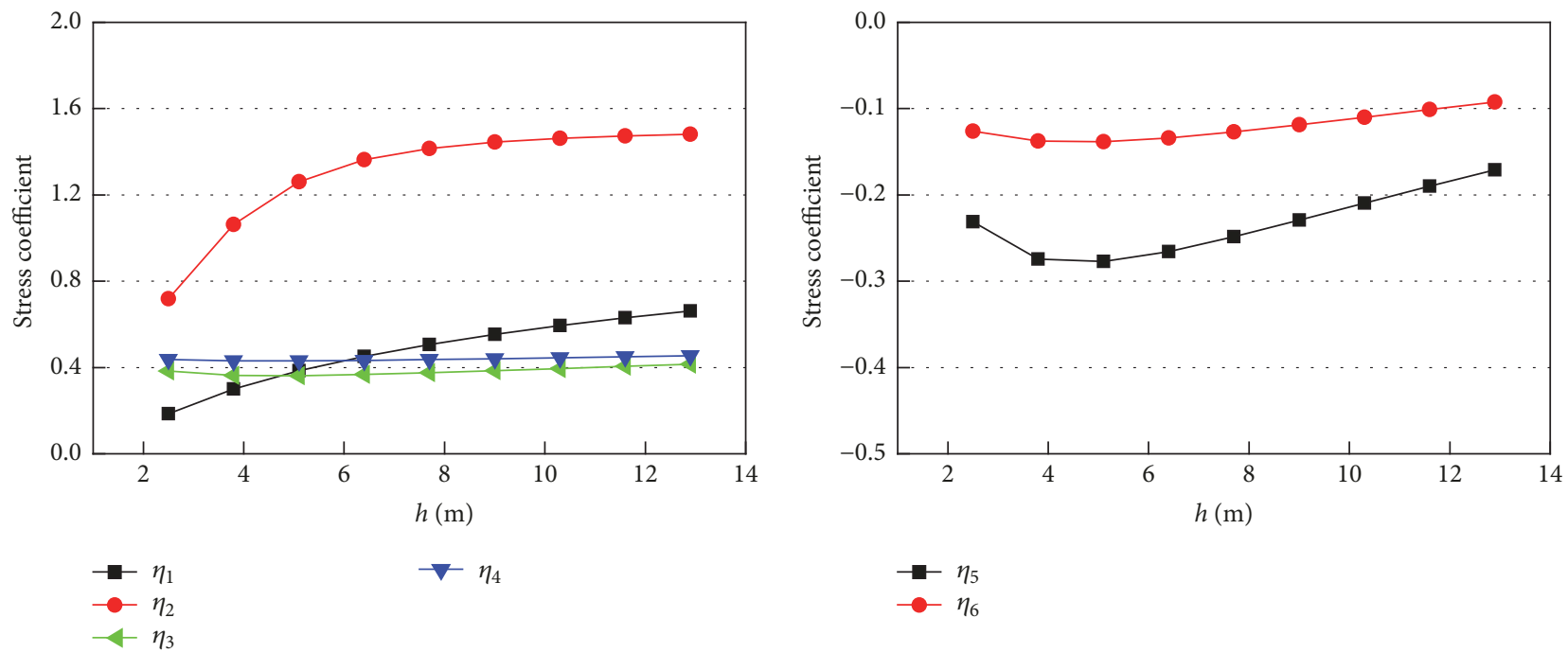

Figure 10: Stress coefficients versus different section height.
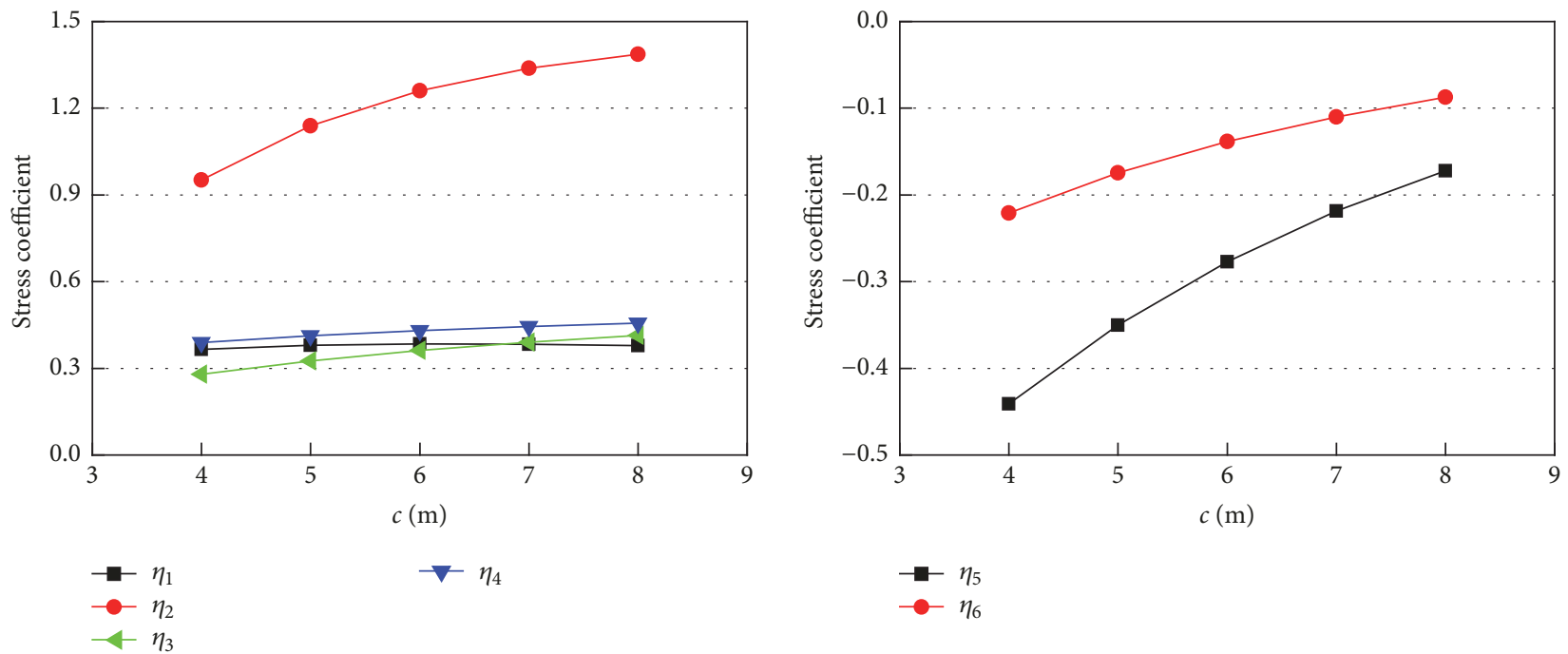

FIGURE 11: Stress coefficients versus different top flange width.

degree, while the shear stress coefficients changed obviously. The coefficients $\eta_{3}$ and $\eta_{4}$ decreased separately from $0.67,0.59$ to 0.27 , and 0.39 , while $\eta_{5}$ and $\eta_{6}$ changed separately from $0.34,0.17$ to $-0.45,-0.22$. It should be noted that the direction of shear stress due to warping torsion and distortion may change as cantilever flange width varied.

6.5. Effect of Bottom Flange Width. When the width of top flange remain unchanged, only the bottom flange width is set to be 3, 3.5, 4, 4.5, 5, 5.5, and $6 \mathrm{~m}$. The variation of stress coefficients is given in Figure 13. The coefficients $\eta_{1}$ and $\eta_{3}$ nearly remained constant as the bottom flange width grew, but other coefficients changed obviously. The normal stress coefficients $\eta_{2}$ and $\eta_{4}$ grew separately from $0.69,0.10$ to 1.26 , 0.43 . The coefficients $\eta_{5}$ and $\eta_{6}$ decreased separately from $-0.46,-0.70$ to $-0.28,-0.13$. So, the influence of bottom flange width is not ignorable.
6.6. Effect of Flange Thickness. When the top and bottom flange thickness is separately $0.20,0.25,0.30,0.35,0.40$, $0.45,0.50 \mathrm{~m}$, the variation of stress coefficients is given in Figures 14 and 15. As shown below, the coefficients $\eta_{1}$ and $\eta_{2}$ in Figure 15 and $\eta_{5}$ and $\eta_{6}$ in Figure 14 changed less than $15 \%$. Other coefficients nearly remained constant as flange thickness varied. It is meant that the stress is almost independent of flange thickness, except that the stress of the slab whose thickness is changed.

6.7. Effect of Web Thickness. Assuming that the general construction of corrugated steel web is unchanged, the web thickness is set to be $0.006,0.010,0.014,0.018,0.022,0.026$, $0.030,0.034$, and $0.038 \mathrm{~m}$. The variation of stress coefficients is given in Figure 16. The coefficients $\eta_{1}$ and $\eta_{2}$ decreased separately from $0.59,1.34$ to $0.02,1.01$, while $\eta_{3}$ and $\eta_{4}$ increase separately from $0.32,0.41$ to $0.49,0.47 . \eta_{5}$ and $\eta_{6}$ changed 

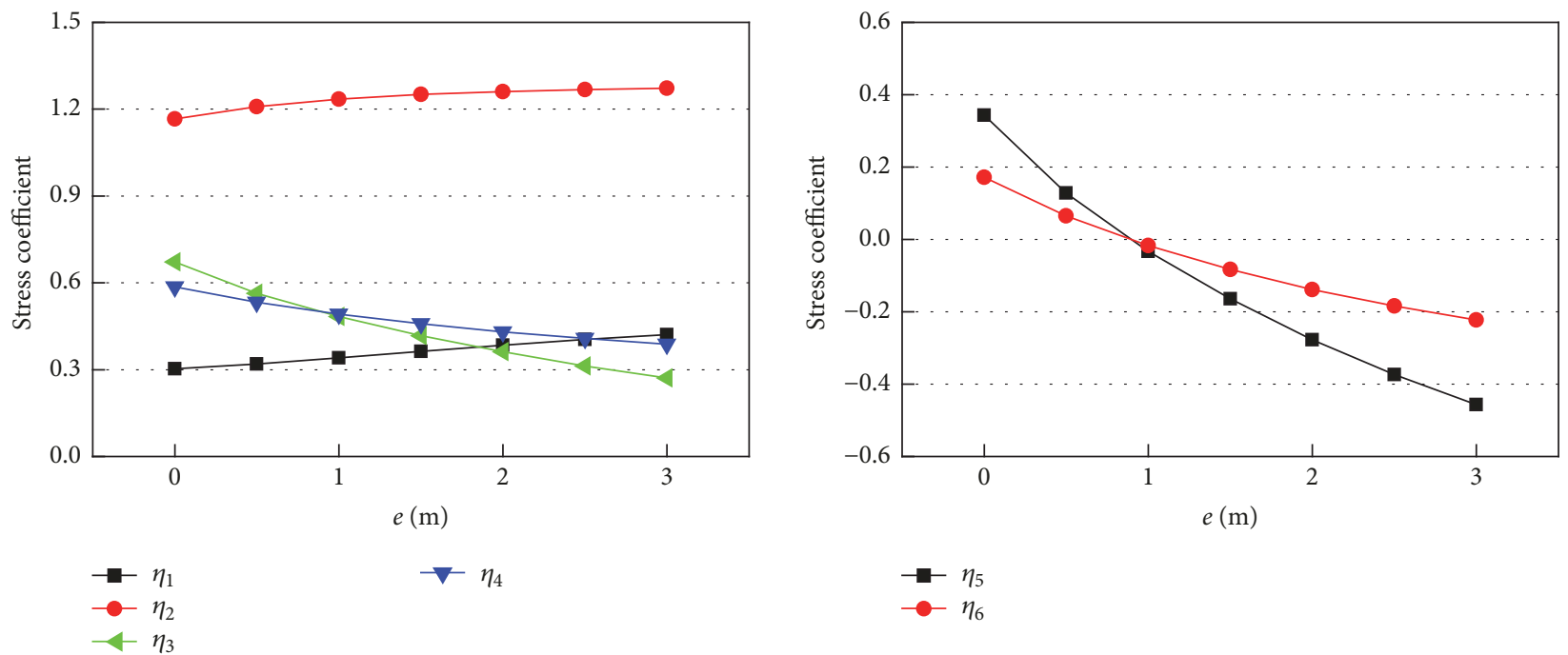

FIGURE 12: Stress coefficients versus different cantilever flange width.
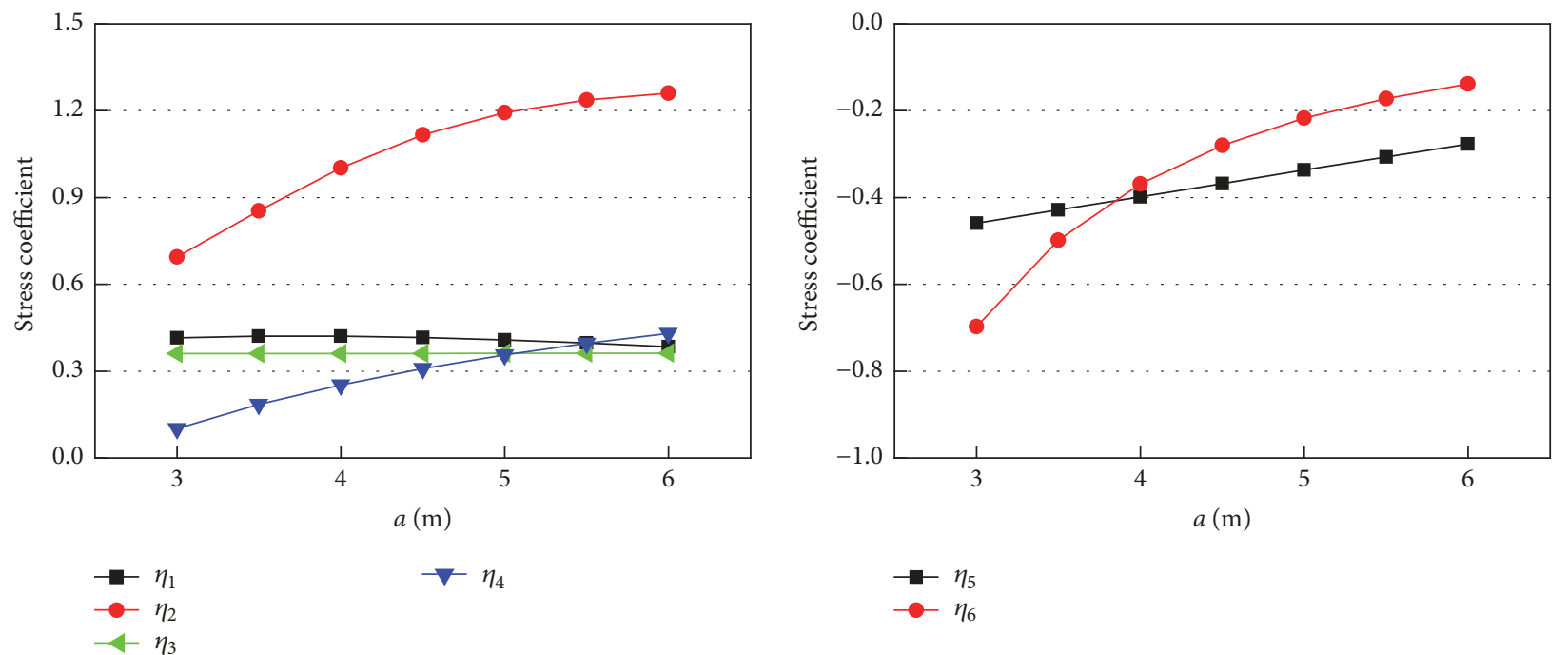

FiguRE 13: Stress coefficients versus different bottom flange width.
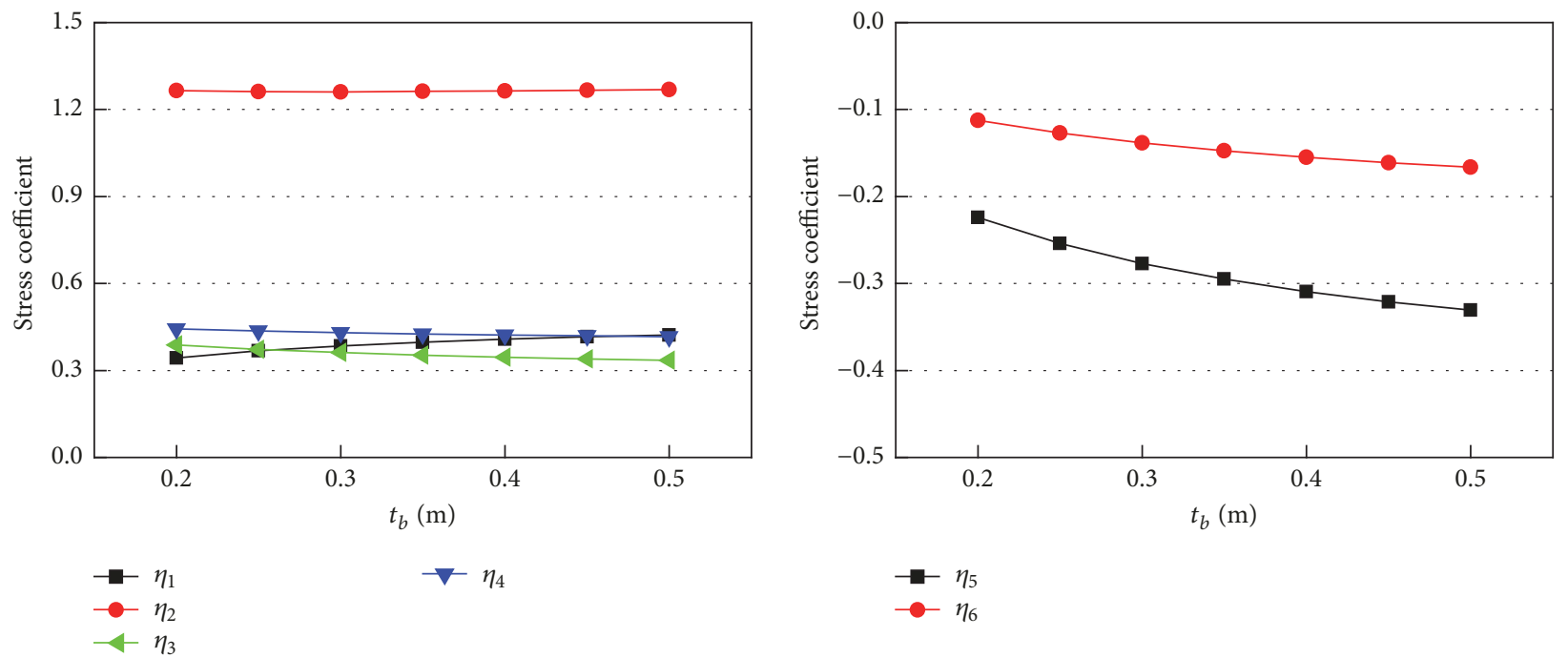

Figure 14: Stress coefficients versus different top flange thickness. 

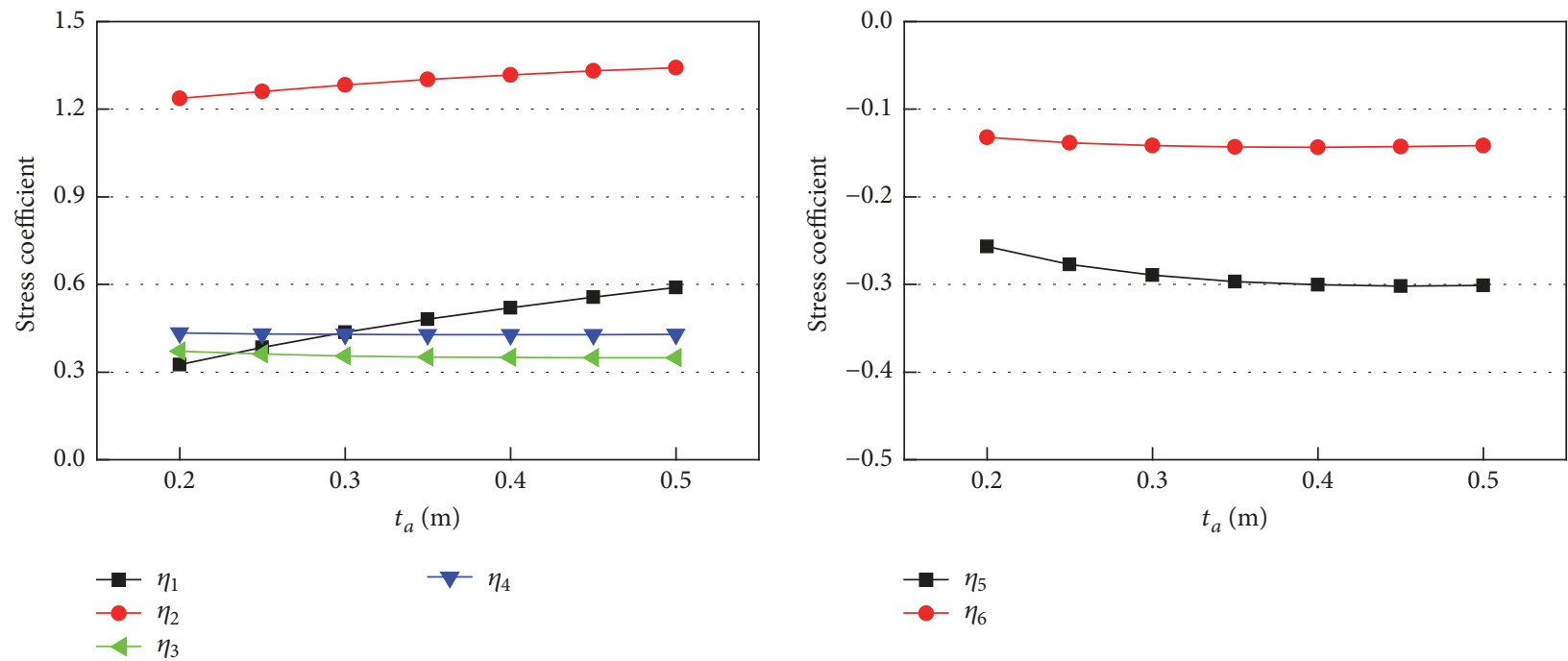

FIGURE 15: Stress coefficients versus different bottom flange thickness.
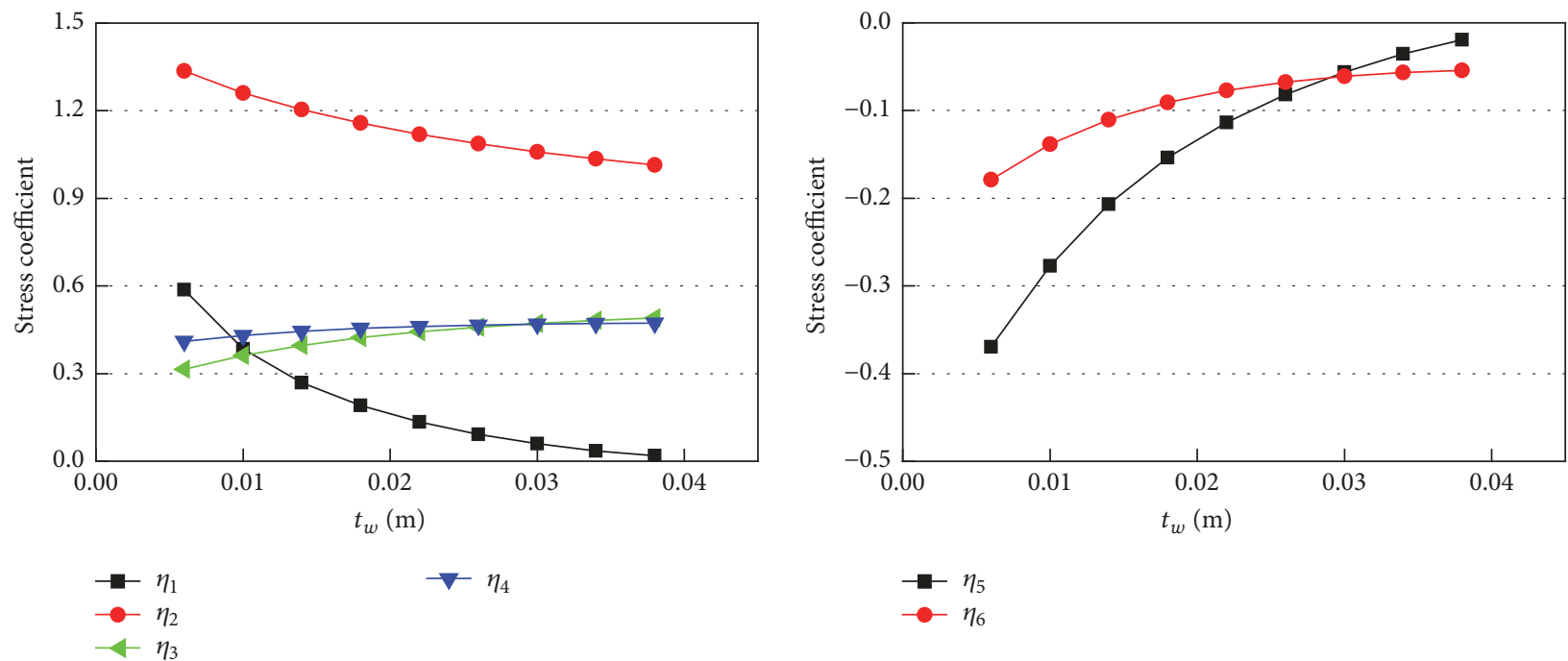

FIgURE 16: Stress coefficients versus different web thickness.

separately from $-0.37,-0.18$ to $-0.02,-0.05$. Results show that web thickness has obvious influence on warping normal stress.

6.8. Effect of Web Construction. As different constructions of corrugated steel web may be adopted in the composite girder, the out-plane bending moment of inertia, $I_{c}$, may be different. So the influence of $I_{c}$ was studied, while the web thickness remained unchanged. The common used constructions of corrugated steel web are listed in Table 1. The variation of stress coefficients is given in Figure 17. It shows the coefficients nearly remained constant, which means the stress due to warping torsion and distortion is independent of the web construction.

\section{Conclusions}

Assuming that the longitudinal axial stiffness of corrugated steel web can be neglected, the formulas for warping torsional and distortional stress were deduced according to the second theory of Umanskii. Based on the revised formulas, this paper has presented a theoretical study on stress of the simple supported composite box girder under eccentric loads. And the influence of varied parameters were studied in detail, including the span length and section height of girder, the width and thickness of top and bottom flange, and the dimensions of corrugated steel web. The following conclusions are obtained.

(1) The accordion of corrugated steel webs should be considered properly in torsion and distortion analysis of composite box girder. The formulas of warping normal stress 
TABLE 1: Common construction dimensions of corrugated steel web.

\begin{tabular}{lccccc}
\hline Type number & 1 & 2 & 3 & 4 & 5 \\
\hline$a_{w} / \mathrm{m}$ & 0.250 & 0.300 & 0.330 & 0.400 & 0.430 \\
$b_{w} / \mathrm{m}$ & 0.200 & 0.260 & 0.270 & 0.340 & 0.370 \\
$d_{w} / \mathrm{m}$ & 0.150 & 0.150 & 0.200 & 0.210 & 0.220 \\
$I_{c} / \mathrm{m}^{4}$ & $4.018 \times 10^{-5}$ & $4.167 \times 10^{-5}$ & $7.333 \times 10^{-5}$ & $7.946 \times 10^{-5}$ & $8.672 \times 10^{-5}$ \\
\hline
\end{tabular}
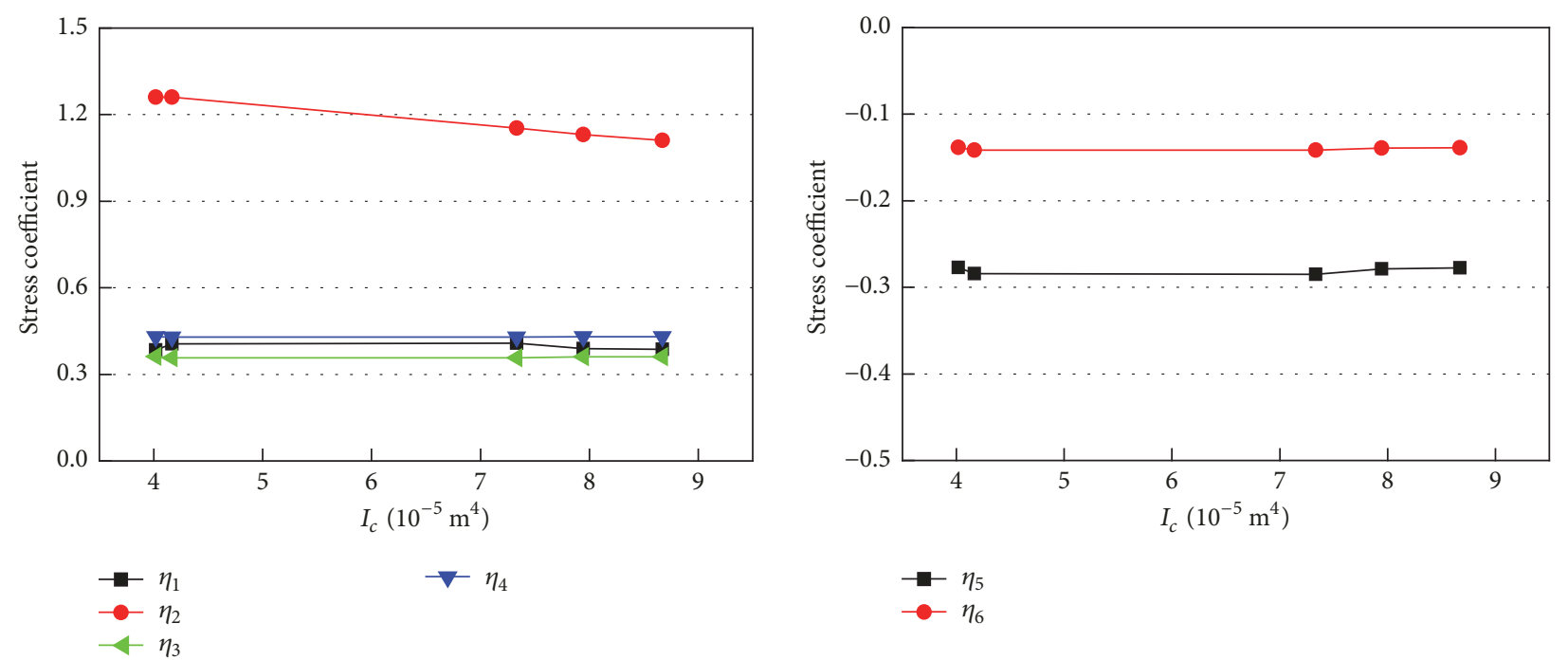

FIGURE 17: Stress coefficients versus different web construction.

and shear stress were revised for analyzing the warping torsion and distortion of the composite box girder of corrugated steel webs. Comparing with the FEA results, the revised formulas are proved to be more effective.

(2) The results show that the influences of warping torsion and distortion are more significant if the girder is shorter, which is easily acceptable. However, even though the whole girder rigidity may increase by enlarging the section dimensions, the warping normal stress and shear stress may not decrease at all. According to studies in this paper, in order to reduce the warping stress ratio, it is suggested to increase the girder span length and the thickness of corrugated steel web height or reduce the girder height and the top, bottom, and cantilever slab width. To reduce the web shear stress ratio, it is suggested to increase the cantilever flange width flange width or reduce the bottom slab width. The thickness of concrete flange and the web construction have a limited impact on both kinds of stress.

(3) As for common composite box girders with corrugated steel webs under eccentric loads, the warping torsion and distortion may cause considerable warping normal stress of shear stress. The total warping normal stress may be as big as flexural normal stress, and the total shear stress is usually 30 to 50 percent of flexural shear stress. Accordingly, it is recommended that both the warping normal stress of concrete flanges and shear stress of corrugated steel webs should be included in stress calculating, when eccentric loads are imposed on composited girders.

(4) The FEA results showed a special feature that the shear stress were different in flat panel and inclined panel of corrugated steel webs, as illustrated in Figure 6. So the detailed mechanical mechanism of corrugated steel webs under different shearing conditions should be studied in future.

\section{Conflicts of Interest}

The authors declare that there are no conflicts of interest regarding the publication of this paper.

\section{Acknowledgments}

The work described herein is part of a research project funded by the National Natural Science Foundation of China (no. 51308053 and no. 51608069) and Chinese Universities Scientific Fund of Chang'an University (no. 300102288110).

\section{References}

[1] M. Cheyrezy and J. Combault, "Composite bridges with corrugated steel webs-achievements and prospects," in BSE Symp.: Structures including New Materials, pp. 479-484, IABSE, Zürich, Switzerland, 1990.

[2] Y. L. Mo, C.-H. Jeng, and Y. S. Chang, “Torsional behavior of prestressed concrete box-girder bridges with corrugated steel webs," ACI Structural Journal, vol. 97, no. 6, pp. 849-859, 2000 (English).

[3] Y. L. Mo and Y.-L. Fan, "Torsional design of hybrid concrete box girders," Journal of Bridge Engineering, vol. 11, no. 3, pp. 329-339, 2006 (English). 
[4] H. J. Li, J. S. Ye, S. Wan, and Y. Wang, "Mechanical performances of box girder with corrugated steel webs under eccentric loading," Journal of Traffic and Transportation Engineering, vol. 4, no. 2, pp. 23-26, 2004 (Chinese).

[5] B. D. Liu, W. Z. Feng, H. W. Ren, P. F. Li, and K. Mou, "Experimental study on torsion and distortion of continuous rigid frame bridge with corrugated steel webs," China Railway Science, vol. 36, no. 4, pp. 40-46, 2015 (Chinese).

[6] B. W. Yang, Y. L. Li, S. Wan, and J. D. Zhang, "Stress analysis of box girder with corrugate steel webs under torsion," Journal of South China University of Technology (Natural Science Edition), vol. 40, no. 2, pp. 19-22, 2012 (Chinese).

[7] J. Di, X. H. Zhou, J. L. You, and X. F. Kong, “Torsional property of prestressed concrete composite beam with corrugated steel webs," Journal of Chang'an University (Natural Science Edition), vol. 29, no. 3, pp. 58-63, 2009 (Chinese).

[8] S. B. Wang, "Mechanical properties of pre-stressed concrete composite box girders with corrugated steel webs under eccentric loading," Zhongguo Gonglu Xuebao/China Journal of Highway and Transport, vol. 25, no. 6, pp. 68-73, 2012 (Chinese).

[9] X. F. Nie and Q. H. Zhang, "Study on the torsion and distortion effect of concrete box-girder with corrugated steel webs influenced by the critical factors," Building Science Research of Sichuan, vol. 40, no. 5, pp. 46-49, 2014 (Chinese).

[10] Y. Y. Chen, B. C. Chen, and S. Lin, "Experiment of torsional performance and finite element analysis of PC composite box girder with corrugated steel webs," Journal of Architecture and Civil Engineering, vol. 28, no. 4, pp. 106-115, 2011 (Chinese).

[11] Y. Ding, K. Jiang, and Y. Liu, "Nonlinear analysis for PC boxgirder with corrugated steel webs under pure torsion," ThinWalled Structures, vol. 51, pp. 167-173, 2012 (English).

[12] Y. Ding, K. Jiang, F. Shao, and A. Deng, "Experimental study on ultimate torsional strength of PC composite box-girder with corrugated steel webs under pure torsion," Structural Engineering and Mechanics, vol. 46, no. 4, pp. 519-531, 2013 (English).

[13] C. Kondo, T. Kobayashi, Y. Shimizu, and M. Hattori, "Design and construction of a composite box girder bridge with corrugated steel webs: shinkai bridge," Bridge and Foundation Engineering, vol. 28, no. 9, pp. 13-20, 1994 (Japanese).

[14] L. Liu and D. S. Qian, "Behavior of corrugated steel webs under loading," Journal of the China Railway Society, vol. 22, supplement 1, pp. 53-56, 2000 (Chinese).

[15] R. P. Johnson and J. Cafolla, "Corrugated webs in plate girders for bridges," Proceedings of Institute of Civil Engineering Structures and Bridge, vol. 123, no. 2, pp. 157-164, 1997 (English).

[16] Y. H. Zhang and L. X. Lin, "Research on warping stress of restrained torsion for thin-walled box girder under eccentric axial load," Gongcheng Lixue/Engineering Mechanics, vol. 30, no. 3, pp. 32-36, 2013 (Chinese).

[17] Y. R. Hu, L. Liu, and Y. H. Zhang, "Torsional geometrical properties of box section with inclined webs," Journal of Central South University (Science and Technology), vol. 46, no. 7, pp. 2558-2563, 2015 (Chinese).

[18] L. Li, X. Bai, and Y. H. Zhang, "Research on twist center and principal sectorial coordinate of thin-walled box section," Journal of Lanzhou Jiaotong University, vol. 32, no. 4, pp. 96-100, 2013 (Chinese).

[19] J. Q. Guo, Z. Z. Fang, and Z. Zheng, Design Theory of Box Girder, China Communication Press, Beijing, China, 2008.

[20] H. J. Li, Experimental study and analysis on torsion and distortion of box-girder with corrugated steel webs [Ph.D. thesis], Southeast University, Nanjing, China, 2003 (Chinese).
[21] Q. Xu and S. Wan, Design and Application for Prestressed Concrete Box-Girder Bridges with Corrugated Steel Webs, China Communication Press, Beijing, China, 2009. 


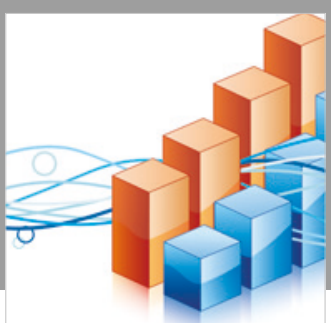

Advances in

Operations Research

\section{-n-m}
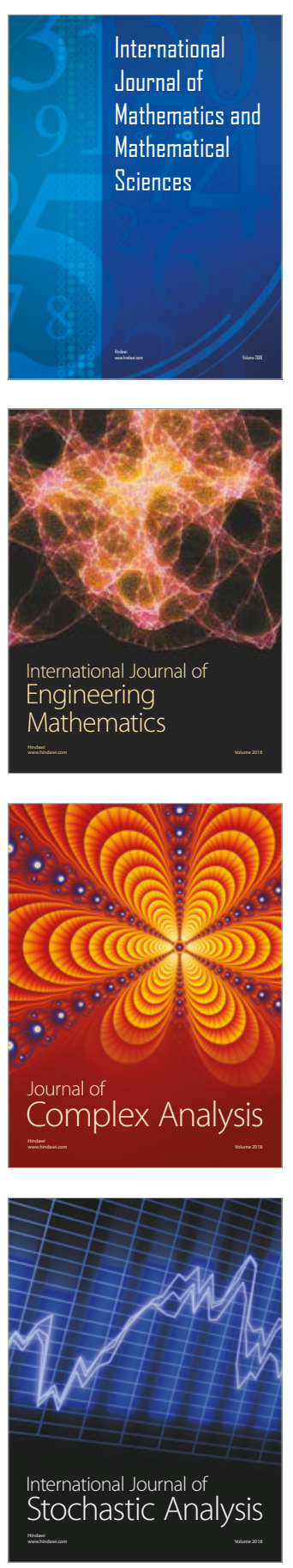
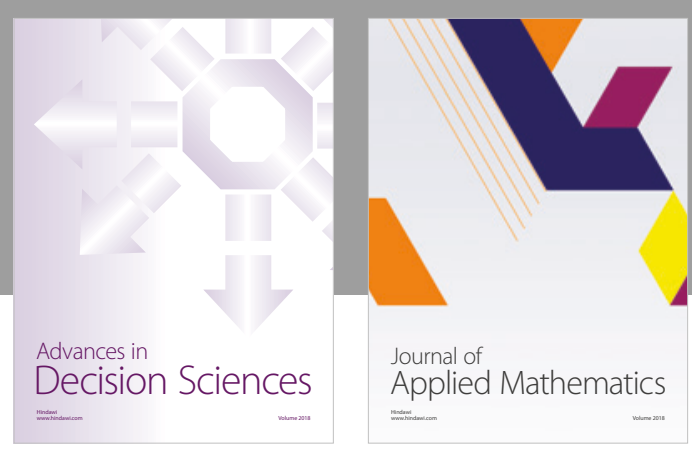

Journal of

Applied Mathematics
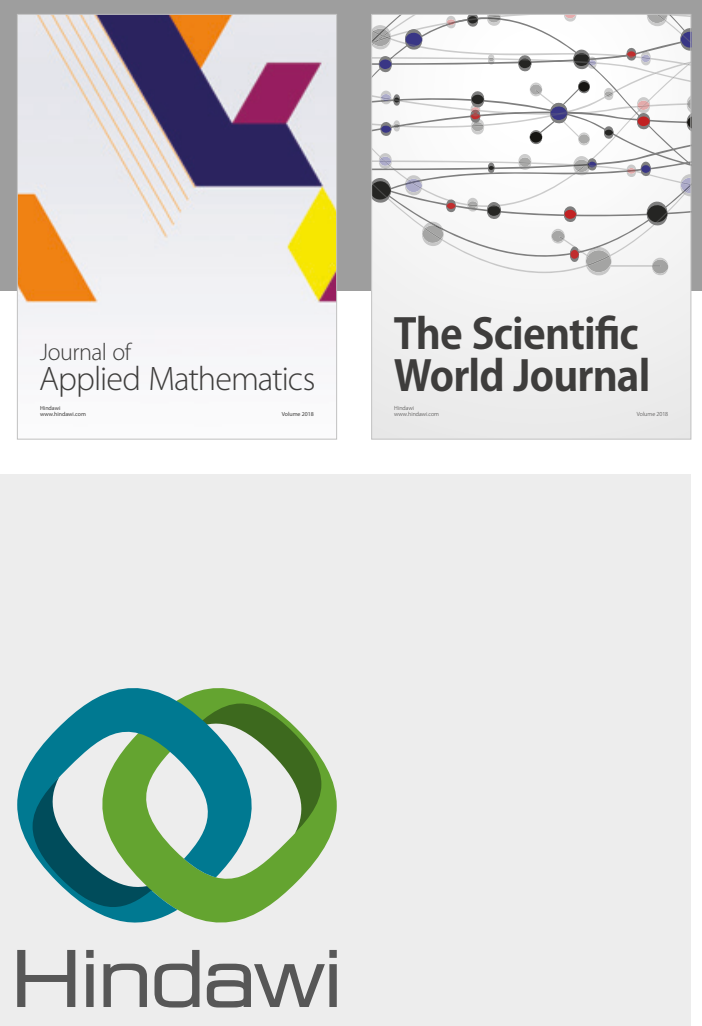

Submit your manuscripts at

www.hindawi.com

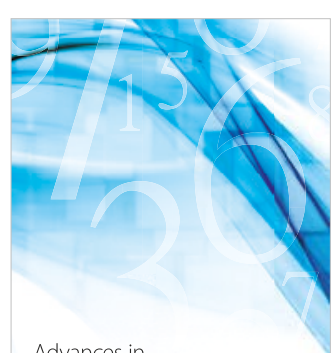

Advances in
Numerical Analysis
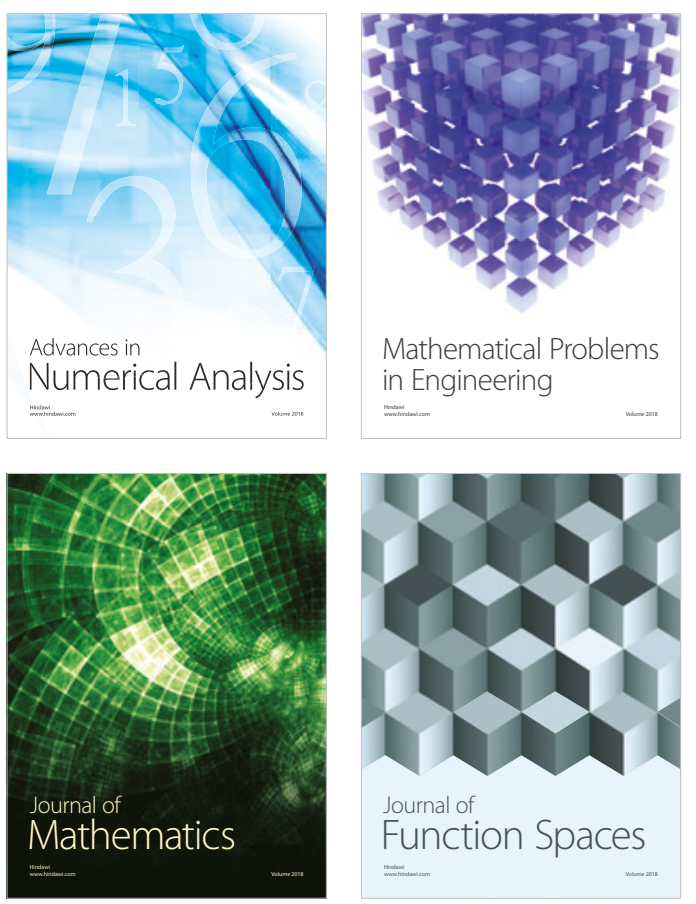

Mathematical Problems in Engineering

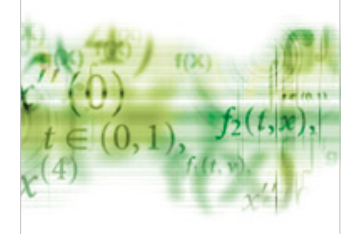

International Journal of

Differential Equations

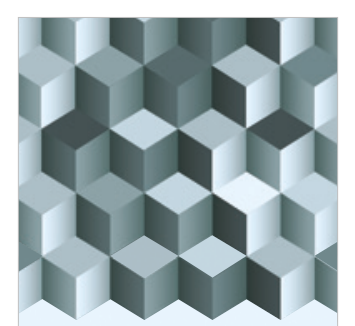

Journal of

Function Spaces

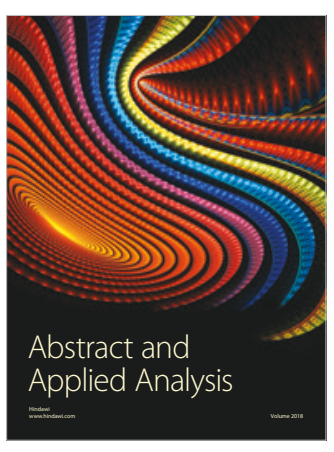

The Scientific

World Journal

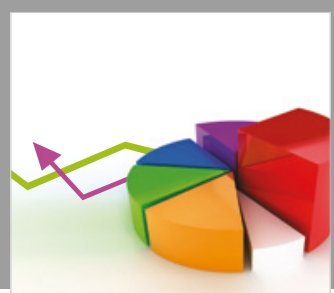

Journal of

Probability and Statistics
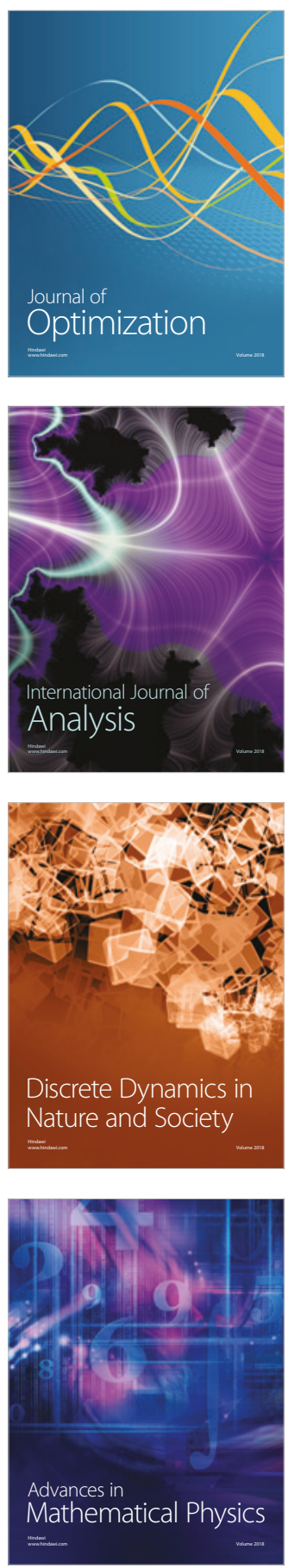